\title{
Możliwości i ograniczenia spawania rurowych złączy różnoimiennych spoinami o odmiennej grani
}

\author{
The opportunities and limitations of the welding \\ of dissimilar pipe joints using welds with different roots
}

\section{Streszczenie}

Praca zawiera opis zachowania niejednorodnego złącza spawanego po procesie modernizacji. Rozważane złącze zostało wykonane ze stali konwencjonalnej i używanej obecnie stali nowej generacji. Rozważano problemy powstawania naprężeń i odkształceń spawalniczych w spoinach. Model opisuje zachowanie różnoimiennych złączy zbudowanych ze stali konwencjonalnych (X20) i nowej generacji (VM12). Na kilku ilustracjach zaprezentowano mechanizmy oddziaływania naprężeń i odkształceń w tego typu złączach.

Słowa kluczowe: złącza niejednorodne; właściwości mechaniczne; naprężenia spawalnicze; degradacja termomechaniczna

\begin{abstract}
The purpose of the paper is to present the mechanism of heterogeneous welded joints during the process of the retrofit. The considered joints are made of conventional steels used in the power industry, as well as new - generation steels. The problems of failure and the design of such joints are considered in the paper. The model of heterogeneous welded joint was built with properties of conventional (X20) steel and a new generation steel of VM12 type. A few illustrations presenting the mechanism of the deformation and failure of the welded joints are presented.
\end{abstract}

Keywords: heterogeneous welded joint; mechanical properties; failure of welded joints; thermomechanical ratchet

\section{Wstęp}

Instalacje ciepłownicze są permanentnie przystosowywane do pracy w coraz trudniejszych, często ekstremalnych warunkach dla stosowanych w nich materiałów.

Działania te polegają $\mathrm{m}$. in. na wprowadzaniu nowych, specjalnie projektowanych i przystosowywanych do wysokich temperatur i ciśnień stopów, wydłużaniu czasu pracy - wydawałoby się już wyczerpanych termomechanicznie materiałów - w oparciu o dokładniejszą ekstrapolację ich właściwości, przeprowadzaniu modernizacji, zmianach konstrukcyjnych kotłów i in.

Aktualnym problemem towarzyszącym remontom, odtwarzaniu instalacji ciepłowniczych i budowie nowych jest wykonywanie złączy zawierających różne materiały podstawowe, dodatkowe - a w efekcie hybrydowe spoiny. Inny materiał stosowany jest na wykonanie grani, a inny na ściegi wypełniające i licujące spoin. Cele, którym przyporządkowane są te operacje są zróżnicowane.

Grań wykonuje się:

- stalą łatwospawalną (zwykle niekosztowną),

- materiałem niewymagającym stosowania gazu osłonowego i poduszki gazowej (mieszanki formującej) wewnątrz złącza rurowego,

- inną technologią niż pozostałe warstwy w celu uzyskania pełnego i dokładnie ukształtowanego przetopu, niezaburzającego przepływu medium. Często stosuje się tu me- todę TIG (141) z wykorzystaniem nieco odmiennego materiału dodatkowego niż pozostałe wypełnienie spoiny,

- stopem utrudniającym propagację wodoru dyfundującego lub dyfuzję reaktywną węgla.

Niekiedy możliwy jest dobór materiału dodatkowego spełniającego szereg powyższych cech. Ogólną regułą wykonywania złączy spawanych jest wypełnienie spoin stopem najbliższym chemicznie materiałem łączonym, a w przypadku spawania złączy różnoimiennych kryterium jest jego dobór do łatwiej spawalnego z nich.

Stosowanie materiału dodatkowego jako trzeciego zdarza się w odosobnionych przypadkach - nie tylko dla wypełnienia grani - np. podczas spawania żeliwa, stali chromowych, stali średnio- i wysokowęglowych i szeregu innych trudnotopliwych materiałów. Jest coraz częstsze również w energetyce $[1 \div 4]$

Hybrydyzacja spoin prowadzi do szeregu zjawisk nakładających się na standardowe, a w efekcie komplikujących problemy eksploatacyjne złączy pracujących w warunkach obciążeń termomechanicznych $[5 \div 8,10,11]$. Jeżeli stosuje się inne od zasadniczych materiałów dodatkowych do spawania - wyłącznie w celu wykonania grani spoiny lub nałożenia warstwy na ścianki rowka, mogą pojawić się problemy już podczas wykonywania złączy, które zarówno technologowie spawalnicy, jak i spawacze powinni poznać i opanować.

Dr inż. Kwiryn Wojsyk - Zakład Spawalnictwa Politechnika Częstochowska; mgr inż. Wojciech Pawełczyk - PGE Bełchatów.

Autor korespondencyjny/Corresponding author: kwiryn@gmail.com 
Wiążą się one z powstawaniem naprężeń i odkształceń podczas i po spawaniu oraz:

- możliwymi trudnościami w uzyskaniu odpowiednich właściwości wytrzymałościowych i odbiorczych,

- niezdeterminowaną pracą i degradacją złączy w procesie wieloletniej eksploatacji w warunkach zmiennych obciążeń termomechanicznych.

Naprężenia i odkształcenia w rurowych złączach spawanych występują wskutek nierównomiernego nagrzewania ich wewnętrznej i zewnętrznej powierzchni oraz bliższych i dalszych obszarów od osi spoin. W efekcie powstają od-

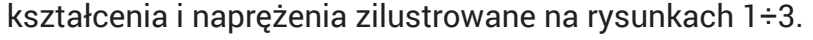

Mechanizm ich powstawania można opisać następująco:

Wskutek nagrzewania obwód rur ulega spęczeniu (skróceniu) na swej długości, przez co utworzona spoina kurcząc się naciska na przyspoinowe części rur, powodując ich ściskanie. Spoina jest rozciągana i w przypadku braku zapasu plastyczności może pękać w jednym lub wielu miejscach na obwodzie. Pęknięcia te są równoległe do tworzącej walca (ich powstaniu sprzyjają naprężenia oznaczone w dalszej części pracy kierunkiem $x-x$ ). Ponieważ spawanie nie odbywa się równocześnie na całym obwodzie rury, naprężenia rozciągające $w$ kierunku równoległym do osi spoiny nie rozkładają się symetrycznie wokół osi rury, przyjmując zmienne wartości, których kład po obrocie o 900 w płaszczyźnie rysunku pokazano na rysunku 3.

Materiały łączone są nagrzewane na swej grubości nierównomiernie, a wskutek intensywniejszego nagrzania rur od strony źródła ciepła, materiał zostaje nagrzany na szerszym odcinku od strony lica niż grani spoiny. W konsekwencji spoina ulega asymetrycznemu spęczeniu w tym kierunku, wywołując rozciąganie zarówno przylicowych, jak i przygraniowych partii złącza (dalszej części pracy kierunek naprężeń oznaczono jako z-z). Efekt ten wzmacniający zjawisko pokazane na rysunku 1, ilustruje rysunek 2 .

Opisane powyżej dwa z trzech mechanizmów powstawania naprężeń rozciągających w kierunkach x-x i z-z, (rozciąganie na grubości - pominięto) zachodzą wyłącznie wskutek nagrzania i ochłodzenia osiowosymetrycznych elementów spawanych i występują niezależnie od spiętrzeń naprężeń związanych z wadami kształtu spoiny, przemianami strukturalnymi, warunkami eksploatacji, pełzaniem statycznym i cyklicznym. Dodatkowo zachodzą efekty wynikające z różnorodnych właściwości fizycznych i mechanicznych w tworzącej się spoinie i łączonych materiałach. Ich działanie dotychczas fragmentarycznie zbadane podczas złożonych warunków eksploatacyjnych może być przyczyną dodatkowych naprężeń, odkształceń lub pęknięć i w ich wyniku - awarii konstrukcji.

Precyzyjne wyznaczenie wielkości naprężeń spawalniczych jest niezwykle trudne ze względu na złożoność zjawisk mechanicznych zachodzących w metalu spoiny i strefy wpływu ciepła. W przypadku jednoosiowego stanu naprężeń, gdy nie osiągają one wartości granicy plastyczności, nie wywierają istotnego wpływu na wytrzymałość konstrukcji. Przy spawaniu grubych przekrojów powstaje często przestrzenny stan naprężeń, który może być przyczyną powstania kruchego złomu złącza.

Dokonując obliczeń dla różnych typów spoin i dla różnych warunków spawania należy uwzględnić fakt, że na wielkość naprężeń i odkształceń spawalniczych wpływ ma nie tylko technologia, lecz również kształty przekrojów, grubości elementów oraz usytuowanie spoin. Najbardziej prawdopodobnymi czynnikami wpływającymi na rozkład naprężeń własnych są:

- właściwości materiałów spawanych,

- energia liniowa spawania,

- wielkość i kształt rowka,
- kolejność układania ściegów,

- warunki spawania (temperatura materiału i otoczenia),

- warunki umocowania elementów spawanych.
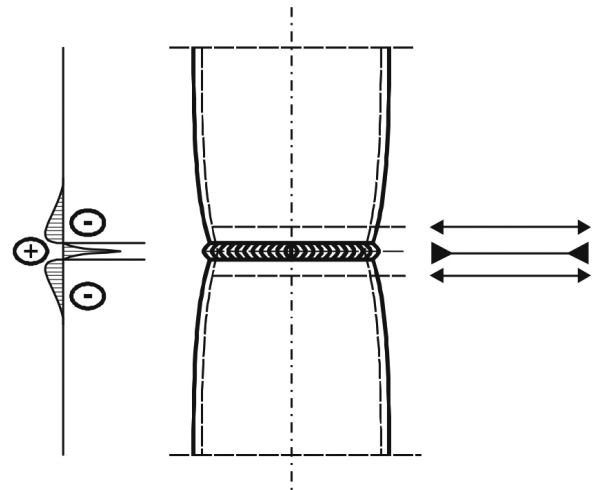

Rys. 1. Spawane złącze rurowe $z$ demonstracją efektu rozciągania spoiny i ściskaniem strefy wokółspoinowej

Fig. 1. Welding of pipe joints with demonstration of weld stretching effect and weld area compression

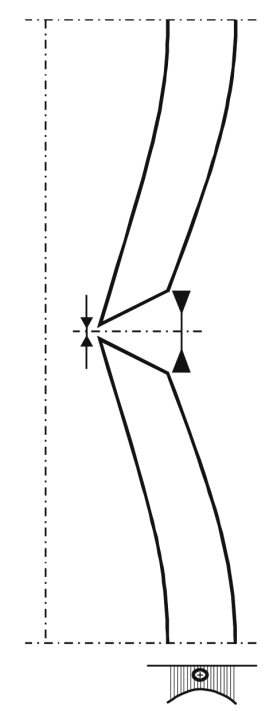

Rys. 2. Schemat przyczyny powstawania naprężeń w kierunku z-z w rurowym złączu spawanym

Fig. 2. The scheme explaining reasons of stress formation in the $z-z$ direction in a pipe weld joint

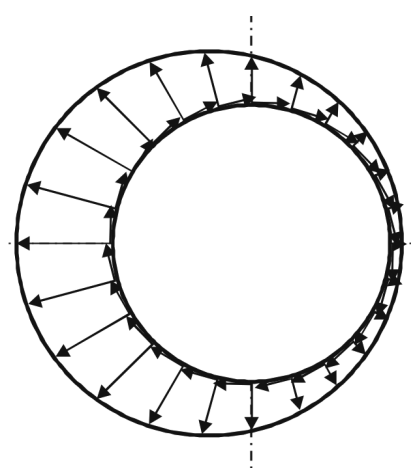

Rys. 3. Rozkład naprężeń rozciągających wzdłuż obwodu spoiny z wykonanym kładem o 90 stopni w płaszczyźnie rysunku - na płaszczyznę prostopadłą do osi spoiny

Fig. 3. The tensile stress distribution along the weld circumference with $90^{\circ}$ projection on a plane perpendicular to the axis of the weld

W tych miejscach złącza, w których występują karby kształtu i odchyłki metalurgiczne tj. na liniach wtopienia od strony lica i grani spoiny powstaje spiętrzenie naprężeń, których 
wielkość uzależniona jest od wielu czynników, takich jak: obecność i wielkość podtopienia, kąt między nadlewem a materiałem, promień przejścia między materiałem spawanym a nadlewem, wysokość nadlewu lica i grani, niejednorodność składu chemicznego, struktury, zróżnicowanie twardości, powierzchnia zakończenia krystalizacji itp. (rys. 4).

Przykładem współczesnej implementacji heterogenicznych spoin $w$ różnoimiennych złączach spawanych są połączenia rur ze stali VM12 z rurami ze stali X20 o średnicy $44 \mathrm{~mm}$ i grubości ścianki 6,3 mm wykonane różnymi materiałami dodatkowymi: warstwa graniowa drutem o składzie chemicznym odpowiadającym stali X20, natomiast warstwy wypełniające - stali VM12.

Właściwości mechaniczne i skład chemiczny materiałów podstawowych i dodatkowych przedstawiono w tabelach I- VIII. Materiały podstawowe:

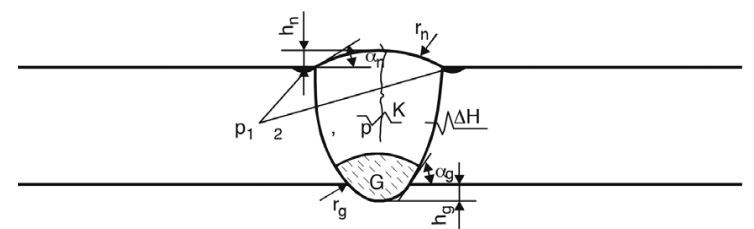

Rys. 4. Złącze spawane $z$ potencjalnymi niezgodnościami; $p_{1}, p_{2}$ - podtopienie, $a_{n}, a_{g}$ - kąt między nadlewem, a materiałem, $r_{n}, r_{g}$ - promień przejścia między spoiną a materiałem rodzimym, $h_{n}, h_{g}$ - wysokość nadlewu od strony lica i grani spoiny, $\Delta \mathrm{H}$ - zmiana twardości wokół linii wtopienia, $\mathrm{K}$ - powierzchnia końca krystalizacji spoin, G - grań spoiny

Fig. 4. The weld joint with potential dissidences; $p_{1}, p_{2}-$ undercut, $a_{n}, a_{g}-$ angle between the reinforcement and material, $r_{n}, r_{g}-$ the transition radius between a weld and a parent material, $h_{n}, h_{g}-$ reinforcement height measured at the weld face and the root, $\Delta \mathrm{H}$ - the change in hardness around a weld line, $\mathrm{K}$ - the surface of the end of weld crystallization, $\mathrm{G}$ - root of the weld

Tablica I. Własności mechaniczne martenzytycznej stali energetycznej X20CrMoV121 wg PN-EN 10216-2 Table I. The mechanical properties of martensitic steel X20CrMoV121 according to PN-EN 10216-2

\begin{tabular}{|c|c|c|c|c|c|c|c|c|c|}
\hline \multirow{3}{*}{ Oznaczenie } & \multicolumn{4}{|c|}{$\begin{array}{c}\text { Właściwości mechaniczne } \\
\text { w temperaturze } 20^{\circ} \mathrm{C}\end{array}$} & \multirow{2}{*}{\multicolumn{4}{|c|}{$\begin{array}{c}\text { Wytrzymałość na pełzanie } \\
\mathbf{R}_{\mathbf{z} 100000}[\mathrm{MPa}] \\
\text { Temperatura }\left[{ }^{\circ} \mathrm{C}\right]\end{array}$}} & \multirow{3}{*}{$\begin{array}{l}\text { Temperatura } \\
\text { pracy w } \\
{\left[{ }^{\circ} \mathrm{C}\right]}\end{array}$} \\
\hline & \multirow{2}{*}{$\begin{array}{c}\mathrm{Rm} \\
\mathrm{MPa}\end{array}$} & \multirow{2}{*}{$\begin{array}{l}\mathrm{Re}_{\text {min }} \\
\mathrm{MPa}\end{array}$} & \multirow{2}{*}{$\begin{array}{c}A_{5} \\
\%\end{array}$} & \multirow{2}{*}{$\frac{\mathrm{KV}}{\mathrm{J}}$} & & & & & \\
\hline & & & & & 500 & 550 & 570 & 600 & \\
\hline X20CrMoV121 & $690 \div 840$ & 490 & $\min 17$ & $\begin{array}{c}\min 27 / 4 \\
0 * \\
89 *\end{array}$ & 236 & 128 & 95 & 59 & $\leq 585^{\circ} \mathrm{C}$ \\
\hline
\end{tabular}

Tablica II. Skład chemiczny martenzytycznej stali energetycznej X20CrMoV121

Table II. The chemical composition of martensitic steel X20CrMoV121

\begin{tabular}{|c|c|c|c|c|c|c|c|c|c|c|c|c|c|}
\hline \multirow{2}{*}{ Oznaczenie } & \multicolumn{13}{|c|}{ Skład chemiczny \% } \\
\hline & C & Si & Mn & $\mathrm{Ni}$ & $\mathrm{Cu}$ & $\mathrm{Cr}$ & Mo & W & Co & v & $\mathrm{Nb}$ & N & B \\
\hline X20CrMoV121 & $\begin{array}{c}0,17 \\
\div \\
0,23\end{array}$ & $\leq 0,5$ & $\leq 1,00$ & $\begin{array}{c}0,30 \\
\div \\
0,80\end{array}$ & - & $\begin{array}{c}10,0 \\
\div \\
12,5\end{array}$ & $\begin{array}{c}0,80 \\
- \\
1,20\end{array}$ & - & - & $\begin{array}{c}0,25 \\
\div \\
0,35\end{array}$ & - & - & - \\
\hline
\end{tabular}

Tablica III. Właściwości mechaniczne badanej stali VM12-SHC w temp. $20^{\circ} \mathrm{C}$ (wg atestu producenta)

Table III. The mechanical properties of tested steel VM12-SHC at $20^{\circ} \mathrm{C}$ (according to producer's certificate)

\begin{tabular}{|c|c|c|c|c|}
\hline $\begin{array}{c}\mathbf{R}_{\mathbf{e}} \\
{[\mathrm{MPa}]}\end{array}$ & $\begin{array}{c}\mathbf{R}_{\mathbf{m}} \\
{[\mathrm{MPa}]}\end{array}$ & $\begin{array}{c}\mathbf{A}_{\min } \\
{[\%]}\end{array}$ & HV & $\begin{array}{c}\text { KV } \\
{[\mathrm{J}]}\end{array}$ \\
\hline $552 \div 596$ & $744 \div 784$ & $19,4 \div 21,5$ & $224 \div 254$ & $68,8 \div 81,2$ \\
\hline
\end{tabular}

Tablica IV. Skład chemiczny badanej stali VM12-SHC (wg atestu producenta)

Table IV. The chemical composition of the tested steel VM12-SHC (according to producer's certificate)

\begin{tabular}{|c|c|c|c|c|c|c|c|c|}
\hline \multicolumn{10}{|c|}{ Zawartość pierwiastków [\%] } & V & W & Co & Inne \\
\hline C & Si & Mn & Cr & Mo & V & & & $\mathrm{B}-0,005$ \\
& & & & & & & $\mathrm{~N}-0,047$ \\
$\mathrm{Nb}-0,04$ \\
$\mathrm{Ni}-0,24$ \\
\hline
\end{tabular}

Materiały dodatkowe:

- dla stali VM12

Tablica V. Właściwości mechaniczne zastosowanego spoiwa WZCrCoW12-2-2 w temp. $20{ }^{\circ} \mathrm{C}$ (wg atestu producenta) Table V. The mechanical properties of applied binding material WZCrCoW12-2-2 at $20^{\circ} \mathrm{C}$ (according to producer's certificate)

\begin{tabular}{|c|c|c|c|}
\hline $\begin{array}{c}\mathbf{R}_{\mathbf{e}} \\
{[\mathrm{MPa}]}\end{array}$ & $\begin{array}{c}\mathbf{R}_{\mathbf{m}} \\
{[\mathrm{MPa}]}\end{array}$ & $\begin{array}{c}\mathbf{A}_{\text {min }} \\
{[\%]}\end{array}$ & $\begin{array}{c}\mathbf{K V} \\
{[\mathrm{J}]}\end{array}$ \\
\hline 560 & 720 & 17 & 27 \\
\hline
\end{tabular}


Tablica VI. Skład chemiczny zastosowanego spoiwa W ZCrCoW1 1-2-2 (wg atestu producenta)

Table VI. The chemical composition of applied binding material WZCrCoW12-2-2 (according to producer's certificate)

\begin{tabular}{|c|c|c|c|c|c|c|c|c|}
\hline \multicolumn{9}{|c|}{ Zawartość pierwiastków [\%] } \\
\hline C & Si & Mn & $\mathrm{Cr}$ & Mo & v & w & Co & Inne \\
\hline 0,145 & 0,37 & 0,45 & 11,68 & 0,26 & 0,201 & 1,44 & 1,640 & $\begin{array}{c}\mathrm{N}-0,042 \\
\mathrm{Nb}-0,050 \\
\mathrm{Ni}-0,38 \\
\mathrm{Cu}-0,04\end{array}$ \\
\hline
\end{tabular}

- dla stali X20

Tablica VII. Właściwości mechaniczne zastosowanego spoiwa W CrMoWV12Si w temp. $20^{\circ} \mathrm{C}$ (wg atestu producenta)

Table VII. The mechanical properties of applied binding material WCrMoWV12Si at $20^{\circ} \mathrm{C}$ (according to producer's certificate)

\begin{tabular}{|c|c|c|c|}
\hline $\begin{array}{c}\mathbf{R}_{\mathbf{e}} \\
{[\mathrm{MPa}]}\end{array}$ & $\begin{array}{c}\mathbf{R}_{\mathbf{m}} \\
{[\mathrm{MPa}]}\end{array}$ & $\begin{array}{c}\mathbf{A}_{\min } \\
{[\%]}\end{array}$ & $\begin{array}{c}\text { KV } \\
{[\mathrm{J}]}\end{array}$ \\
\hline 590 & 700 & 15 & 35 \\
\hline
\end{tabular}

Tablica VIII. Skład chemiczny zastosowanego spoiwa W CrMoWV12Si (wg atestu producenta)

Table VIII. The chemical composition of applied binding material WCrMoWV12Si (according to producer's certificate)

\begin{tabular}{|c|c|c|c|c|c|c|c|c|}
\hline \multicolumn{9}{|c|}{ Zawartość pierwiastków [\%] } \\
\hline C & Si & Mn & $\mathrm{Cr}$ & Mo & v & W & $\mathrm{Ni}$ & Inne \\
\hline 0,194 & 0,37 & 0,55 & 11,14 & 0,95 & 0,25 & 0,42 & 0,11 & $\begin{array}{c}N-0,015 \\
N b-0,010 \\
C u-0,05\end{array}$ \\
\hline
\end{tabular}

Do zespawania rur wykorzystano metodę TIG (141), stosując jako gaz ochronny argon(II), a jako gaz formujący - mieszankę gazową $\mathrm{H}_{2} / \mathrm{N}_{2}(\mathrm{~F} 2)$.

Gotowe złącza poddano różnorodnym obróbkom cieplnym w zakresie temperatur $650 \div 790{ }^{\circ} \mathrm{C}$ w różnych okresach czasu od 0,5 do $72 \mathrm{~h}$, a następnie przeprowadzono nieniszczące badania wizualne (VT) i radiograficzne (RT) w zakresie 100\% z uwzględnieniem poziomu jakości B wg PN-EN ISO 5817.

Wykonano szereg badań niszczących: sprawdzono wytrzymałość złączy na rozciąganie, zginanie, zmierzono rozkłady twardości w strefach wokółspoinowych oraz przeprowadzono badania metalograficzne makro- i mikroskopowe $[1,2]$. W wyniku tych badań wykazano, że pospawalnicza obróbka cieplna złączy tego typu jest konieczna, a najlepsze wyniki wytrzymałościowe uzyskuje się podczas wyżarzania złączy w temperaturze $770{ }^{\circ} \mathrm{C}$ przez ok. 1 godzinę. Wykazano, że dłuższe niż godzinowe czasy wyżarzania prowadzą zarówno do obniżenia udarności złączy, a w szczególności spoin, jak i zmniejszenia ich wytrzymałości na rozciąganie. W wyniku wyżarzania

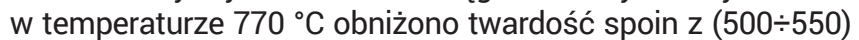
HV10 do maksymalnie 320 HV10, osiągając również radykalny spadek gradientów twardości w złączach.

W próbkach zginanych uzyskiwano kąty gięcia $180^{\circ}$ bez wystąpienia rys i pęknięć na rozciąganych powierzchniach próbek. Podczas rozciągania zerwanie następowało poza spoinami w materiale rodzimym X20 na średnim poziomie $786 \mathrm{MPa}$. Praca łamania (KV) złączy obrobionych $w$ ten sposób wynosiła minimum $33 \mathrm{~J}$ w spoinie średnio $110 \mathrm{~J}$ w strefach wpływu ciepła zarówno gdy karb nacinany był od strony lica, jak i grani spoiny.

Wyniki wszelkich przeprowadzonych badań odpowiadają właściwościom zgodnym z wymogami technologicznymi [1].

Dobrze wykonane złącza to tylko pierwszy warunek ich przydatności. Dalsze objawiają się w procesie długoletniej eksploatacji [9]. Jedną z możliwych metod badań jest długofalowa obserwacja obejmująca zachowanie się konstrukcji w całym okresie jej eksploatacji.

W tym celu skonstruowano model rurowego hybrydowego złącza spawanego złożonego z 1470 elementów połączonych
4579 węzłami zestawionego z 5 oddzielnych stref materiałowych (rys. 5) od dołu i materiału miękkiego o mniejszej niż górny odporności na pełzanie (M I), strefy I wpływu ciepła spoiny (SWC I), spoiny (S), strefy II wpływu ciepła spoiny (SWC II) i materiału o znacznej wytrzymałości mechanicznej i odporności na pełzanie (M II). Model ten poddano termomechanicznym obciążeniom charakterystycznymdla napełniania i zrzutu pary, doprowadzając do chwilowych przeciążeń, charakterystycznych dla inkubacyjnych stanów przedawaryjnych w instalacjach energetycznych. Założono, że sytuacje te mogą wystąpić kilkanaście razy w okresie 300 tysięcy godzin pracy instalacji.
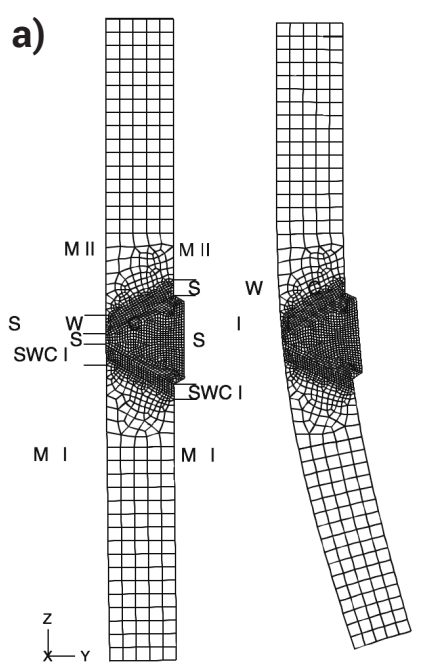

b)

Rys. 5. Model hybrydowego złącza spawanego: a) ścianka rury z podziałem na strefy o zróżnicowanych właściwościach mechanicznych i różnej odporności cieplno-mechanicznej, b) widok rozpatrywanego złącza

Fig. 5. The model of a hybrid weld joint: a) the wall of the pipe divided into zones of different mechanical properties and various thermo-mechanical resistance, b) the view of analyzed joint 
Zachowanie się złącza w warunkach słabo dotychczas poznanego zjawiska cieplnego odkształcenia przyrostowego (ratchetingu) zaprezentowano po jednym otaz wielu cyklach nagrzewania-chłodzenia, obserwując naprężenia zredukowane Hubera-Misesa-Hencky'ego, naprężenia normalne w kierunkach X-X i Z-Z (rys. 5) oraz odkształcenia plastyczne w jednostkach bezwymiarowych.

Na rysunkach $6 \div 9$ zaprezentowano wycinkowe wyniki ba-

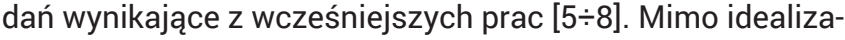
cji kształtu złącza - niezdeformowanie kształtu grani - widoczne jest, że to właśnie wokół niej następuje największa

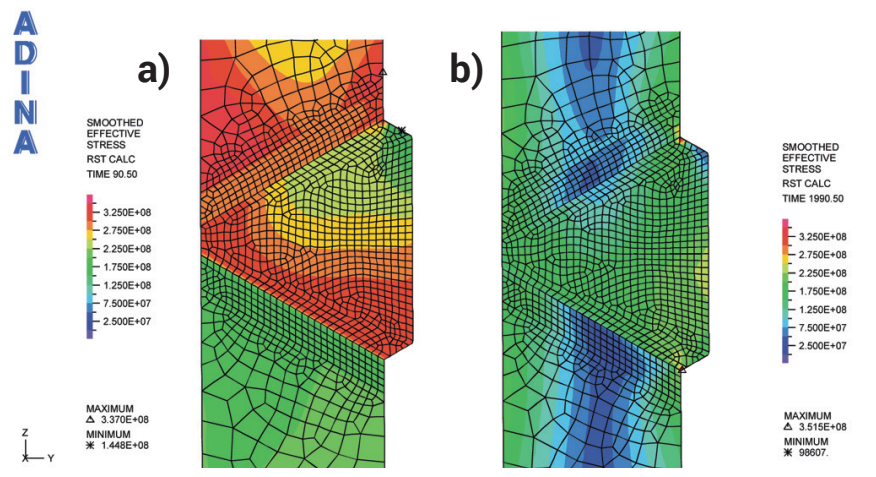

Rys. 6. Naprężenia zredukowane w złączu: a) w szczytowym punkcie temperaturowym pierwszego cyklu (lewa strona) i b) po zakończeniu końcowego cyklu obciążenia (prawa strona)

Fig. 6. The reduced stress in the joint: a) at the temperature peak in the first cycle (left side), b) after the end of the loading cycle (right side)

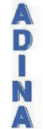

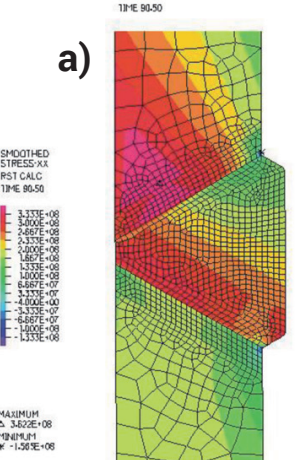

b)

$\varliminf_{-v}^{2}$

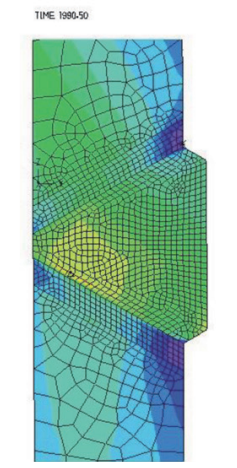

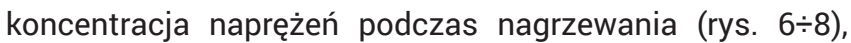
a odkształcenia plastyczne koncentrują się tam, gdzie zwykle występuje tzw. biała strefa (rys. 9b), tj. tam, gdzie powstająca i poszerzająca się warstwa gruboziarnistego ferrytu ulega ustawicznej degradacji podczas wieloletniej eksploatacji tracąc swą odporność na obciążenia udarowe.

Obecność odmiennego materiału w grani pogłębia te procesy. Należy zatem, mimo możliwości osiągnięcia pozytywnych rezultatów wykonania złączy pokazanych na przykładzie złącza VM12 - X20 postępować szczególnie ostrożnie w procesie ich dalszej eksploatacji.
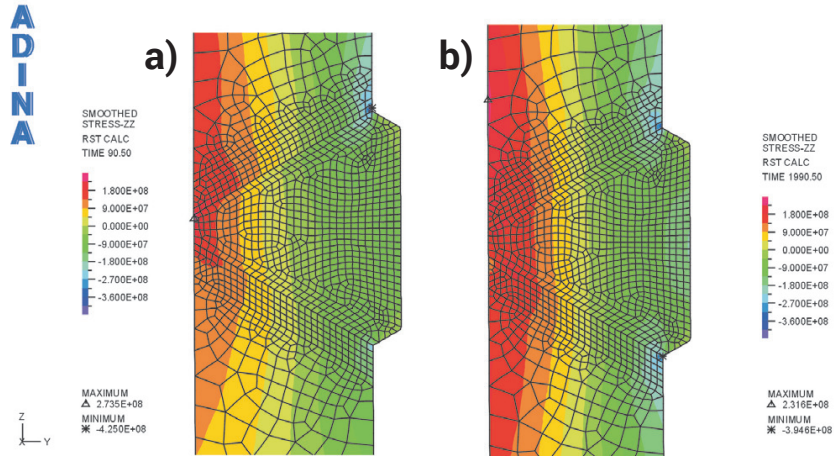

Rys. 8. Naprężenia normalne w kierunku z - z w złączu w szczytowym punkcie pierwszego cyklu (lewa strona) - a) i po zakończeniu końcowego cyklu obciążenia termomechanicznego (prawa strona) - b)

Fig. 8. The normal stresses in the z-z direction in analyzed joint: a) at the temperature peak in the first cycle (left side), b) after the end of the thermomechanical loading cycle (right side)
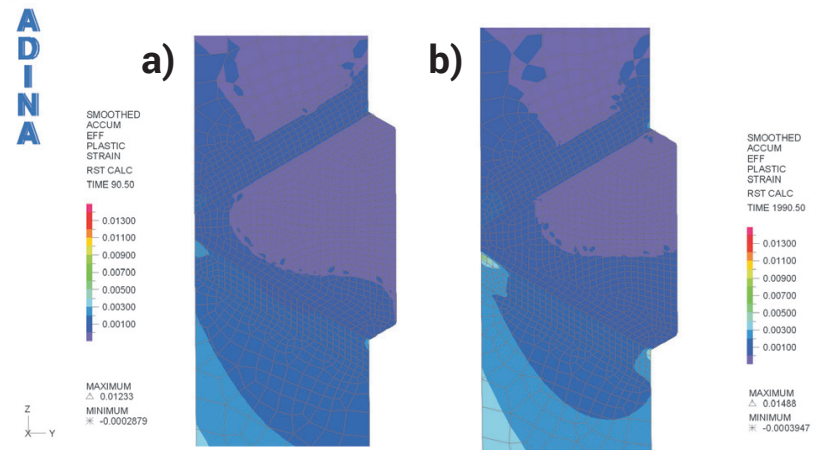

Rys. 9. Odkształcenia plastyczne podczas osiągnięcia przez złącze szczytowej temperatury w pierwszym cyklu (lewa strona) - a) o po zakończeniu końcowego cyklu obciążenia termomechanicznego (prawa strona) - b)

Fig. 9. The plastic deformations of weld joint a) at the temperature peak in the first cycle (left side), b) after the end of the thermomechanical loading cycle (right side)

\section{Wnioski}

Spoiny złożone z co najmniej dwóch materiałów dodatkowych do spawania mogą być stosowane w energetycznych złączach rurowych pod warunkiem przeprowadzania dokładnych badań odbiorczych i prowadzeniu długoletnich badań kontrolnych.

Trudności w ich implementowaniu wynikają z trzech grup problemów:

- dodatkowych komplikacji w wykonaniu i obróbkach cieplnych,

- powstawaniu dodatkowych efektów odkształceniowo-naprężeniowych i reaktywno-dyfuzyjnych,

- złożonej degradacji podczas ich wieloletniej eksploatacji w instalacjach energetycznych.

\section{Literatura}

[1] Pawełczyk W.: Właściwości złączy jednorodnych i niejednorodnych z udziałem stali VM12 i X20CrMoV121. Praca dyplomowa studiów podyplomowych o specjalności: „Wytwarzanie i remonty kotłów”. Promotor. dr inż. Kwiryn Wojsyk Częstochowa 2014 r.
[2] Jasak J., Wojsyk K., Golański G.: Właściwości mechaniczne niejednorodnego złącza spawanego stali VM12/X20 po wyżarzaniu. Przegląd Spawalnictwa $4 / 2015$ str. $5 \div 9$. 
[3] Jasak J., Golański G., Wojsyk K., Kupczyk J.: Niejednorodne złącza spawane spoiwem EPRI P87 - mikrostruktura i właściwości. Hutnik - Wiadomości Hutnicze, 2014, nr 5, str. 337 $\div 340$.

[4] Wrona A.: Technologia spawania stali energetycznych $w$ gatunku $\mathrm{X} 10 \mathrm{Cr}$ MoVNb9-1 ze stalą w gatunku 10CrMo9-10. Praca dyplomowa studiów podyplomowych „Wymagania i kompetencje międzynarodowego inżyniera spawalnika - IWE" Częstochowa 2014. Promotor. dr inż. Kwiryn Wojsyk.

[5] Wojsyk K.: Analiza mechanizmu degradacji osiowosymetrycznego złącza spawanego poddanego obciążeniom cieplnomechanicznym. Praca doktorska. Politechnika Częstochowska. Wydział Inżynierii Procesowej, Materiałowej i Fizyki stosowanej. Częstochowa 2007.

[6] Lacki P., Wojsyk K., Służalec A.: The mechanism of failure of the axisymetrical welded joint under thermomechanical loading. Materiały konferencji THERMEC 2009. 6th International Conference on PROCESSING \& MANUFACTURING OF ADVANCED MATERIALS. Berlin, Germany, August $25 \div 29,2009$
[7] Lacki P., Wojsyk K.: Degradacja hybrydowych złączy spawanych w warunkach zmiennych obciążeń cieplnomechanicznych. XVI Międzynarodowa Konferencja Spawalnicza Energetyków. Opole - Jarnołtówek 2008. Materiały Konferencyjne "Spawanie w Energetyce - Zvaranie v Energetike" $23 \div 25.02 .2008$, str. $5 \div 16$.

8] Lacki P. Wojsyk K: Analiza stanu napreżeń i odkształceń w hybrydowych spawanych złączach rurowych poddanych obciążeniom termomechanicznym. Materiały Konferencyjne XIV Konferencji naukowo - technicznej „Postęp, innowacje i wymagania jakościowe procesów spajania” Międzyzdroje $27 \div 29.05 .2008$, str. $145 \div 155$.

[9] Cecotka M., Wnuk M.: Zastosowanie metody spawania wąskoszczelinowego w energetyce. Przegląd Spawalnictwa $7 / 2014$, str. $17 \div 21$.

[10] Grajcar A., Różański M.: Spawalność wysokowytrzymałych stali wielofazowych AHSS. Przegląd Spawalnictwa 3/2014, str. 22 $\div 31$.

[11] Czaplejewicz W., Kondrat Z:: Spawanie kontrolowanej stali Boron 27 Dobór

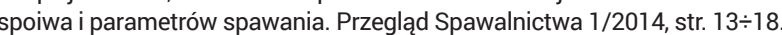

